of what their role is so that the patient can provide informed consent based on this information. If you are not currently doing this and this is the reason for the impaired ability to consent then you are not fulfilling GDC standards.

Since all the author's points can be contested this group of dentists' argument against DA is invalid. I can only assume that this group of people feel their own role is threatened by the idea of DA. In terms of setting up alone, a DT can already do this and so introducing DA is unlikely to see a significant increase in independent practice in competition with existing practices. Dental teams must work together in the interest of the patient and if DA was to go ahead there would be treatment that dental therapists could not carry out so referrals would be made accordingly and this would be best arranged within a single practice. Introducing DA would mean that patients would be able to see the DT for an oral health needs assessment, routine treatment and preventative practice, freeing up time for the dentist to carry out the more complex treatments. Also, a DT's time is cheaper than that of a dentist. How can this change not be seen as a positive move for both patients and the dental team alike? There would be nothing stopping practices working in the existing way so if you personally do not to want to work in this way then fine, don't; but this may work well for some practices and it would be unfair on both the public and the profession to dismiss this idea.

M. Joyce

By email

DOI: 10.1038/sj.bdj.2012.563

\section{PERIODONTAL THERAPISTS}

Sir, on the subject of direct access (DA), your readers may be very interested to read an article by Colleen Rutledge called Heeding the call and committing to periodontal therapy (www.perioandbeyond.com), in which she states that in the USA some dental hygienists (DHs) are being trained as periodontal therapists (PTs), to work in conjunction with the dentist and periodontist. The PT receives training in advanced non-surgical periodontal therapy and is responsible for carrying out phase one treatment within a general practice.

In June 2009 I attended the Eastman Dental Institute for a four day intensive training course on advanced nonsurgical periodontal therapy (NSPT) for the hygienist. This was an immensely enlightening course, covering all aspects from risk factors through aetiology, radiographs, treatment planning and instrumentation. The course was spread over four weeks, with plenty of reading material and revision of notes in between. By the end of the course I had a far better knowledge and understanding of periodontal disease, and most importantly, how to treat my patients in practice. A few months later I undertook the necessary training, again at the Eastman, to administer inferior dental nerve block local anaesthesia.

I consider that, through this training, a new category of hygienist - the PT may evolve as a conduit between dentist and periodontist which many practices would benefit from. It goes without saying that a PT would benefit from DA to patients, though this would inevitably involve diagnosis, which is another bone of contention within the profession. This clinician would be in a position to accept referrals from GDPs, but this service could be offered to a wider range of the general public if treatment was available to potential patients without the necessity of going through a dentist first. The PT could accept patients in their own right from self referrals, just as patients attend a physiotherapist or podiatrist. In turn the PT would be permitted to refer the patients on to a periodontist for more extensive treatment, should the need arise.

Indeed DA for DHs is long overdue and would raise their esteem. Owing to the importance of clinical experience DA should only be considered after a DH has been qualified for five years and I would suggest that advanced training to become a PT should also bear the same condition. More dental schools could offer the same type of course I attended at the Eastman, so that DHs throughout the country would be able to take advantage of this new qualification.

\section{H. Parkin RDH}

By email

DOI: 10.1038/sj.bdj.2012.564

\section{STALKING HORSE}

Sir, I would like to comment on the letter by A. C. L. Holden (No to direct access; BDJ 2012; 212: 355-356). I am a dental hygienist with nearly 30 years' experience in dentistry. I am also an active campaigner for direct access. I've worked full time in general practice for most of that time, only taking time out to work part-time for various dental companies. This was mainly in the software and intra-oral imaging sector. I'm part of the management team in a busy, large, predominantly private, city centre practice. I am also a mentor for the Philips Transitional Support Scheme that supports newly qualified hygienists' move from education to life in practice. I take patient care and safety very seriously.

I believe that Holden may have exposed his lack of years as he appears to have been used as a sort of stalking horse. That is the opinion of a couple of my peers who have read the letter as the argument is very simplistic; on first reading it has merit but on deeper investigation holds no water.

D. Bridges RDH

By email

DOI: 10.1038/sj.bdj.2012.565

\section{DRACONIAN REFERRAL SYSTEM}

Sir, I wish to reply to the recent letter the letter by A. C. L. Holden (No to direct access; BDJ 2012; 212: 355-356). I totally disagree with the points raised regarding dental hygienist-therapists and direct access to patients. I found the tone and content of the letter derogatory to dental hygienist-therapists.

I would like to clarify a couple of points. Holden claims that as dental hygienists-therapists have a shorter professional education than dentists it is therefore beyond our competency to diagnose dental conditions. Additionally, that dental surgeons are often the health professional patients see most frequently, so they are the health professional relied upon to diagnose oral conditions such as oral cancer and mucosal disorders. He then goes on to suggest that giving non-suitably trained professionals such as dental hygienist-therapists responsibility to diagnose such conditions is bordering upon neglecting patients' rights to proper treatment. 
Although dental hygienist-therapists have a shorter professional education, they are trained to the same high standards as dentists. Dental hygienisttherapists are more than capable of working within their remit and knowing when to refer. Most dental hygienist-therapists typically see patients every three months for a routine scale and polish so they see patients just as often, if not more often than a dentist. There is therefore no need for the current 'draconian' referral system.

Dental hygienist-therapists are an invaluable asset to the dental team. Removing the need for a referral from a dentist will not only allow dental hygienist-therapists to carry out their role more effectively, it will also allow better access to dental health care for patients.

\section{H. Griffiths RDT RDH \\ By email}

DOI: 10.1038/sj.bdj.2012.566

\section{A CONSTRUCTIVE DIALOGUE}

Sir, A. C. L. Holden's letter (BDJ 2012; 212: 355-356) saying no to direct access raises the issue of what can be achieved within the length of training courses that hygienists and therapists currently have and whether diagnosis should be included in their courses.

If we look further afield than the UK we see that most courses for dental hygienists and therapists are of similar length to those in the UK and that they already include diagnosis and direct access to patients. Some courses such as those in New Zealand and Australia have allowed therapists to see patients directly for decades.

I would suggest there is still an attitude prevalent in this country that hygienists and therapists are not capable of understanding diagnosis of dental conditions, when in fact the outcomes in current UK courses could not be achieved without a substantial element of diagnostic skill.

Formal training in diagnosis can only enhance the work of dental hygienists and therapists by involving them fully in the decision-making processes used in the assessment of the oral tissues. This surely must be to the greater benefit of patients than the present referral system?
Those who oppose direct access per se should consider both the present and future training needs of hygienists and therapists, their usefulness to patients, and become involved in a constructive dialogue with all concerned with the safety and welfare of patients, seeking to offer ways in which the work of all DCPs can be moved forward in the twenty-first century.

\section{D. Exley Arnside \\ DOI: 10.1038/sj.bdj.2012.567}

\section{LIMITED APPLICABILITY}

Sir, we have thoroughly enjoyed reading the series of articles on Current concepts on the management of tooth wear by Mehta et al. (BDJ 2012; 212: [1-4]). However, we were surprised to read in part 3 that the final occlusal scheme should provide six listed criteria, ${ }^{1}$ which referenced a paper by Stuart et al. in $1963 .{ }^{2}$

In 1963 it was widely believed that it was possible to make an instrument which would accurately reproduce the movements of the mandible; Stuart himself designed a fully adjustable articulator. Further, that it was possible to accurately transfer these movements to a mechanical device, such as an articulator.

Unfortunately, the practical applicability of these beliefs has been limited. Clark et al. ${ }^{3}$ described possible errors that can occur during the different stages of transferring occlusal information to an articulator, while Hangai et $a l .{ }^{4}$ suggested that significant differences were observed in measurements of sagittal condylar inclination in seven types of semi-adjustable articulators using the check bite method. 0'Malley and Milosevic ${ }^{5}$ measured the steepness of the occlusal plane produced by three different semi-adjustable articulators. Significant differences were observed between the results obtained by the Denar and Dentatus articulators (which introduced flattening of the occlusal plane by $5^{\circ}$ and $6.5^{\circ}$ respectively) and those of the cephalogram. Errors associated with programming a fully adjustable articulator relying on a pantographic tracing have also been widely reported. ${ }^{6-8}$

The authors claim that occlusal stability should be based on the principles of a mutually protective occlusal scheme. However, studies involving unrestored dentition demonstrated that relatively few occlusions can be classified in this way. ${ }^{9}$ The validity of this concept has been recently scrutinised against the evidence base from which it was concluded that other functional occlusion types and patterns might be just as acceptable. ${ }^{10}$

Even if accurate transfer of occlusal data and reconstruction to the mutually protective scheme were possible, the suggested criteria ignore the most vital factors in creating a reorganised occlusion: the adaptive capability of the patient, the patient's comfort, and the aesthetic outcome. If Dahl principles were taken into account and full arch reconstructions were undertaken in stages, restoring initially in a reversible manner, the need for complex inaccurate instrumentation would be greatly reduced.

\section{Ryan, M. Kaupas}

By email

1. Mehta S B, Banerji S, Millar B J, Suarez-Feito J-M. Current concepts on the management of tooth wear: part 3. Active restorative care 2: the management of generalised tooth wear. Br Dent J 2012; 212: 121-127.

2. Stuart C, Stallard H. Concepts of occlusion. Dent Clin North Am 1963; 7: 591.

3. Clark J R, Hutchinson I, Sandy J R. Functional occlusion: II. The role of articulators in orthodontics. J Orthod 2001; 28: 173-177.

4. Hangai K, Aridome K, Wang C, Igarashi Y. Clinical evaluation of semi-adjustable articulators: reproducibility of sagittal condylar path inclination assessed by a jaw-tracking system with six degrees of freedom. Nihon Hotetsu Shika Gakkai Zasshi 2008; 52: 360-365.

5. O'Malley A M, Milosevic A. Comparison of three facebow/semi-adjustable articulator systems for planning orthognathic surgery. Br J Oral Maxillofac Surg 2000; 38: 185-190.

6. Coye R B. A study of the variability of setting a fully adjustable gnathologic articulator to a pantographic tracing. J Prosthet Dent 1977; 37: 460-465.

7. Donaldson K, Clayton J A. Comparison of mandibular movements recorded by two pantographs. J Prosthet Dent 1986; 55: 52-58.

8. Hatano Y, Kolling J N, Stern N, Clayton J A. A graphic comparison of mandibular border movements generated by various articulators. Part II: Results. J Prosthet Dent 1989; 61: 425-429.

9. Ogawa T, Ogimoto T, Koyano K. Pattern of occlusal contacts in lateral positions: canine protection and group function validity in classifying guidance patterns. J Prosthet Dent 1998; 80: 67-74.

10. Rinchuse D J, Kandasamy S, Sciote J. A contemporary and evidence-based view of canine protected occlusion. Am J Orthod Dentofacial Orthop 2007; 132: 90-102.

Professor Brian Millar, Dr Subir Banerji and Dr Shamir Mehta respond: We agree with the points in the letter regarding the inability of articulators to completely reproduce jaw movements and that the conditions of the 'ideal occlusion' are 